\title{
Sliding friction of shale rock on dry quartz sand particles
}

\author{
Huijie ZHANG ${ }^{1}$, Shuhai LIU ${ }^{1,2, *}$, Huaping XIAO ${ }^{1,2, *}$ \\ ${ }^{1}$ College of Mechanical and Transportation Engineering, China University of Petroleum-Beijing, Beijing 102249, China \\ ${ }^{2}$ State Key Laboratory of Oil and Gas Resources and Engineering, China University of Petroleum-Beijing, Beijing 102249, China \\ Received: 12 October 2016 / Revised: 09 May 2017 / Accepted: 09 March 2018 \\ (C) The author(s) 2018. This article is published with open access at Springerlink.com
}

\begin{abstract}
The sliding friction of rock, involving all kinds of particles at the contact surface, is relevant to many problems, ranging from those in artificial engineering to earthquake dynamics. In this work, the frictional performance of the shale rock-dry quartz sand contact was investigated using a self-developed testing device. The study showed that the coefficient of friction of the contact increases with nominal stress and that the corresponding friction force increases approximately linearly with nominal stress, which is directly related to the contact stress between each single sand particle and rock shale. An overall dynamic coefficient, $\gamma$, reflecting the response of friction force to nominal stress, first decreases and then increases with area ratio, which is determined by not only the contact stress but also the interparticle friction force. These have important repercussions for a preliminary understanding of the frictional properties of the shale rock-dry quartz sand contact in hydraulic fracturing and related industrial applications.
\end{abstract}

Keywords: shale rock; quartz sand; frictional performance; hydraulic fracturing

\section{Introduction}

Sliding friction of rock is relevant for many problems ranging from artificial engineering to earthquake dynamics [1]. In many practical situations, such as drilling, mining processes, or rock processing, rock is commonly mated with metal/ceramic or other artificial materials [2]. However, both the contact surfaces are rock in earthquake or other natural processes of rock movement, which are also part of the green tribology [3].

The frictional behavior of the different types of rock-cutting tool interfaces has a significant effect on the wear and damage of the cemented carbide used in cutting processes [4-6]. Rock-rock friction, which has been a focus of earthquake research for decades, controls the slip stability of faulting and earthquakes and has been found to decrease with increasing slip velocity [7-10]. Many mechanisms, including powder gel lubrication $[7,11]$, melt lubrication $[9,12]$, and lubrication $[9,13,14]$ have been proposed to explain the reduced friction. The particle size distribution and inter-particle friction influence the nature of deformation and mechanical behavior of granular fault gouges $[15,16]$.

Hydraulic fracturing (HF) is the process by which a fracture is initiated and propagates because of hydraulic loading applied by fluid within the fracture [17]. The fracturing fluid plays an additional significant role, which is to carry and transport proppants into the fracture. As shown in Fig. 1, proppants fill the gap between fracture surfaces to keep the fractures open after the pumping of fracturing fluids is halted, causing high fracturing pressure withdraw, which offers a vast network of pathways for shale gas from reservoir to well. According to Fig. 1, the friction of the proppant in fractures, which determines the distance of proppant transport, plays a significant role in shale gas productivity $[2,18]$. HF is used extensively in the petroleum industry to stimulate shale gas production growth. Because power generation is one of the important aspects of the required energy consumption, it is

*Corresponding authors: Shuhai LIU, E-mail: liu_shu_hai@163.com; Huaping XIAO, E-mail: hxiao@cup.edu.cn 


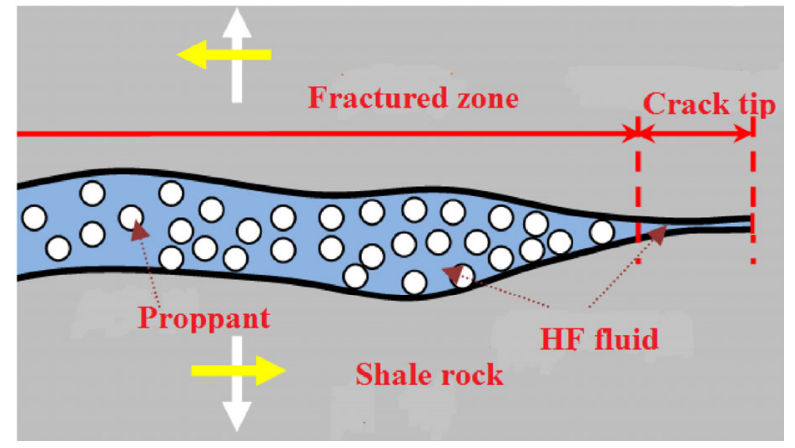

Fig. 1 Schematic illustration of the function of proppant in hydraulic fracturing.

essential to develop methods to save energy in HF [19]. River sand is used predominantly as the proppant in fracturing. The most widely used proppants at present are 20/40 mesh sand, and the proportion of sand of this size used in proppants is $85 \%[5,18]$.

After substantial efforts of researchers, rock frictionsliding is partially understood. Dougherty et al. built a bit-cutter-on-rock tribometry to investigate the tribological behavior of cutter on rock in situ [20]. They discovered that friction between cutter and rock is much higher at low speed than at high speed, which is beneficial to industrial application. Compared to the often studied cutter-rock contact in drilling, mining processes, and rock processing and the rock-rock contact in earthquakes, few researchers have studied the frictional behavior of the shale rock-dry quartz sand contact, which is the basis for investigating the tribological behavior of HF. The goal of this study was to research the frictional behavior of the shale rock-dry quartz sand contact and present a possible explanation for the results obtained, which would provide a preliminary understanding of the shale rock-dry quartz sand contact. The findings of this study are intended to provide helpful information for understanding the influence of load and the amount of quartz sand on the friction between rock and particle and for various industrial production applications including HF [21].

\section{Experimental}

\subsection{Materials}

Shale rock was purchased from the Changxing Slate Corporation (Lushan, China). The dimensions of the upper shale rock and lower shale rock were $20 \mathrm{~mm} \times$ $40 \mathrm{~mm} \times 3 \mathrm{~mm}$ and $50 \mathrm{~mm} \times 100 \mathrm{~mm} \times 3 \mathrm{~mm}$, respectively, as shown in the photograph in Fig. 2. The 3-D microcosmic surface morphology of the shale rock was observed using a surface profilometer (KEYENCE VK-X100 series), and the surface roughness was obtained. The particles used in this work were quartz sand particles, one of the most common types of proppant. The density of the quartz sand was $2,650 \mathrm{~kg} / \mathrm{m}^{3}$, the size was about $620-930 \mu \mathrm{m}$, and the silica content was $80 \%-90 \%$. A photograph of the particles applied in the study is shown in Fig. 3. The shale rock and particles were washed with acetone and ethyl alcohol for $1 \mathrm{~h}$, respectively, cleaned with deionized water, and then dried thoroughly in an oven before the experiments. Only the shale rock-quartz sand contact in the dry condition was studied. Because water is included in real geological formations, the effect of water on the contact should also be considered; however, for simplicity, this effect was not included in this work, which is a basis for investigating the tribological behavior of HF. Water as an important factor will be studied in future work.

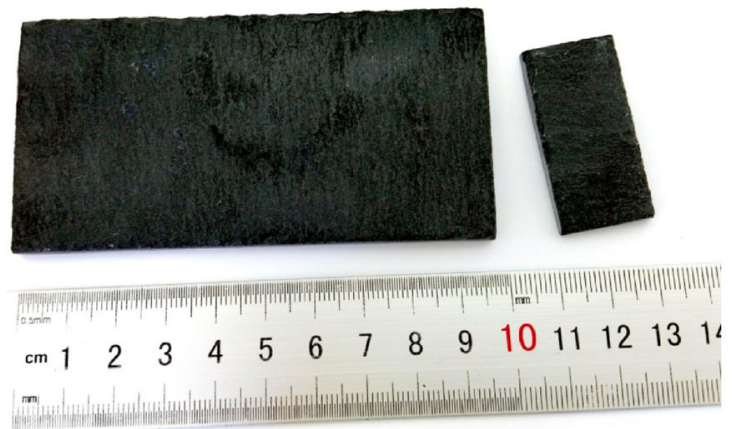

Fig. 2 Shale rock used in this study.

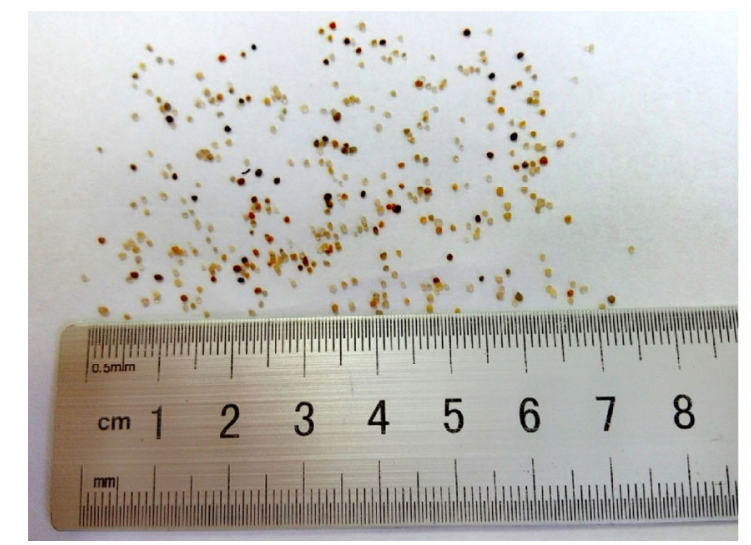

Fig. 3 Sand particles used in this study. 


\subsection{Test instrument}

A three-dimensional diagram of the self-developed experimental system used in this research is shown in Fig. 4. The upper shale rock was fixed on the horizontal beam. The lower shale rock was bonded to the platform with super glue and was moved linearly in the horizontal direction by screw-nut transmission driven by a rotating step motor (TOPCN, Peking, China). Therefore, both the upper and lower shale rock were capable of relative movement, and a force transducer (Lanzhou Institute of Chemical Physics) measured the coefficient of friction of both shale rock contacts. To research the influence of load on the friction, six loads $(1,1.5,2,2.5,4$, and $5 \mathrm{~N})$ and the corresponding nominal stresses obtained by dividing the load by the upper surface area of the upper shale rock $\left(1,250,1,875,2,500,3,125,5,000\right.$, and $\left.6,250 \mathrm{~N} / \mathrm{m}^{2}\right)$ were applied, respectively. To investigate the effect of the amount of sand particles on the friction, six different amounts of sand $(0.06,0.24,0.475,0.95,1.9$, and $3.8 \mathrm{~g}$ ) were distributed uniformly throughout the surface of the lower shale rock. The sliding speed used throughout the study was $1.1 \mathrm{~mm} / \mathrm{s}$, and the unidirectional sliding distance of the lower shale rock was $55 \mathrm{~mm}$ in each test. To reduce the error, experiments were repeated 10 times under each condition. The test

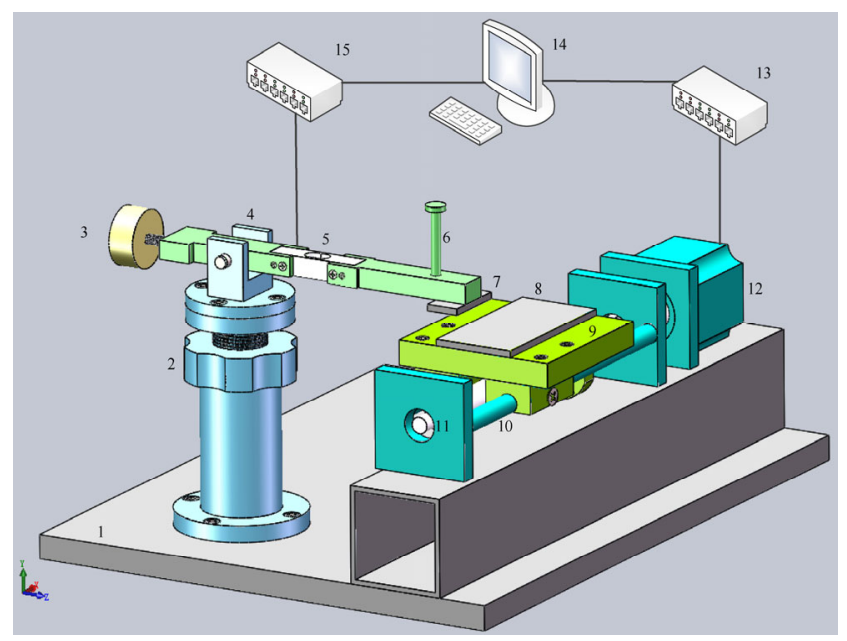

Fig. 4 The 3-D image of the apparatus: 1-Base of apparatus; 2-Height adjusting nut (by nut contacted with bolts); 3-Balance weight; 4-Bearing; 5-Force sensor; 6-Load; 7-Upper shale rock; 8-Lower shale rock; 9-Lower shale platform (fixed with the feed screw nut); 10-Sliding rail; 11-Screw; 12-Step motor; 13-Step motor controller; 14-Computer; 15-Force sensor controller. temperature was maintained at room temperature, about $25^{\circ} \mathrm{C}$, and the relative humidity was about $35 \%$.

\section{Results and discussion}

\subsection{Characterization of shale rock and quartz sand}

The surface roughness of the cleaned shale rock measured by the surface profilometer was $11.47 \pm$ $2.28 \mu \mathrm{m}$ (eight measurements). The Young's modulus $\left(E_{1}\right)$ before sliding of the shale rock determined using a depth sensing indentation technology known as nanoindentation [22] was $35 \mathrm{GPa}$, and the Poisson's ratio $\left(\mu_{1}\right)$ was 0.25 . Figure 5 (Image J) shows the diameter distribution of the sand particles. According to Fig. 5, the average particle size was about $800 \mu \mathrm{m}$. The Young's modulus $\left(E_{2}\right)$ according to the techniques and the analysis methodologies in Ref. [23] using a grain radius of $400 \mu \mathrm{m}$ was $72.6 \mathrm{GPa}$, and the Poisson's ratio $\left(\mu_{2}\right)$ was 0.2 . Five hundred random grains of sand particles were weighed (value of $0.2205 \mathrm{~g}$ ), and the average weight of each one hundred grains of sand particles was obtained by dividing that value by 5 $(0.0441 \mathrm{~g})$. To determine the amount of quartz sand particles in the experiment more accurately, each time $1 \mathrm{~g}$ of sand was gradually placed on the lower shale rock, the particles were arranged tightly without stacking between particles until $3.8 \mathrm{~g}$ of sand took up the entire lower shale rock. The process of the experimental operation is shown in Fig. 6 . The weight of the sand in Fig. 6(a), 6(b), 6(c), and 6(d) is 1, 2, 3, and

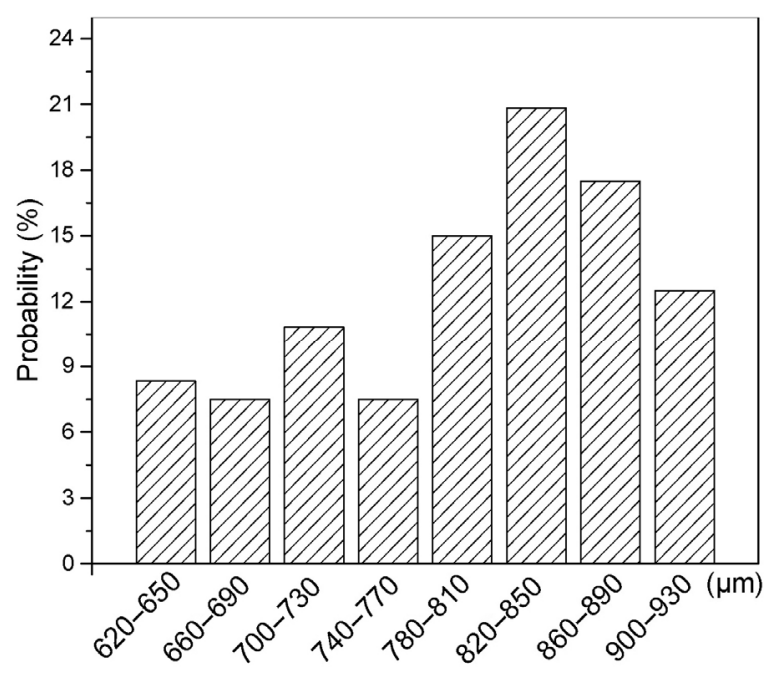

Fig. 5 The diameter distribution of sand particles by Image J. 


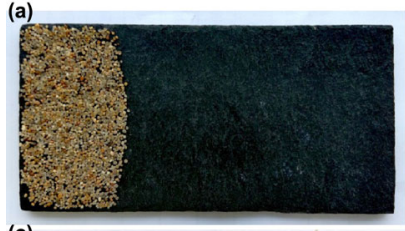

(c)
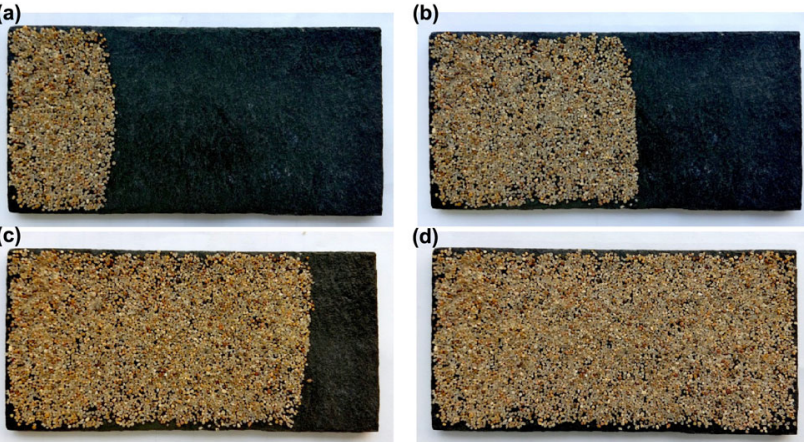

Fig. 6 The photographs of experimental operation that every time $1 \mathrm{~g}$ sand was gradually placed on lower shale rock, the particles were arranged tightly without stacking between particles, until $3.8 \mathrm{~g}$ sand took up the entire lower shale rock. (a) $1 \mathrm{~g}$, (b) 2 $\mathrm{g}$, (c) $3 \mathrm{~g}$, and (d) $3.8 \mathrm{~g}$.

$3.8 \mathrm{~g}$, respectively. To broaden the applications of this study, a dimensionless area ratio was defined as the value determined by $\frac{n \pi r^{2}}{S}$, where $n$ is the number of particles on the lower shale rock, $S$ is the upper surface area of the lower shale rock, and with the assumption that all different sizes of sand particles are equal spheres with a radius $r$ of $400 \mu \mathrm{m}$. Table 1 shows the number of sand particles and the area ratio when $0.06,0.24,0.475,0.95,1.9$, and $3.8 \mathrm{~g}$ of sand were used in this work.

\subsection{Variation of coefficient of friction and friction force with nominal stress}

A self-developed apparatus was used to measure the coefficient of friction (COF) of the contact between the shale rock and the dry quartz sand. The COF variation with a sliding distance of $55 \mathrm{~mm}$ under different nominal stress when the area ratio was $43.29 \%$ is shown in Fig. 7. The mean COF is shown by dashed lines, and the values are given on the right side of the graphs. The corresponding friction force during this sliding

Table 1 The number of sand particles and area ratio at different weight of sand.

\begin{tabular}{ccc}
\hline Weight $(\mathrm{g})$ & Number & Area ratio $(\%)$ \\
\hline 0.06 & 136 & 1.37 \\
0.24 & 544 & 5.47 \\
0.475 & 1,077 & 10.82 \\
0.95 & 2,154 & 21.64 \\
1.9 & 4,308 & 43.29 \\
3.8 & 8,617 & 86.58 \\
\hline
\end{tabular}

is shown in Fig. 8. As shown in Figs. 7 and 8, the COF and friction force fluctuate with the sliding distance. The mean COF values under 1,250, 1,875, 2,500, 3,125, 5,000 , and $6,250 \mathrm{~N} / \mathrm{m}^{2}$ of nominal stress were 0.05993 , $0.08516,0.10826,0.14806,0.1426$, and 0.14648 , respectively, and the corresponding friction force values were $0.05993,0.12774,0.21652,0.37015,0.5704$, and $0.7324 \mathrm{~N}$ (Fig. 8). Figure 9 shows the variation of the mean COF $(0.05993,0.08516,0.10826,0.14806,0.1426$, $0.14648)$ and friction force $(0.05993,0.12774,0.21652$, $0.37015,0.57040 .7324 \mathrm{~N}$ ) with increasing nominal stress. According to Fig. 9, the mean COF increases rapidly, reaches a value of about 0.145 , and then stays roughly constant, while the friction force increases roughly linearly with nominal stress. These results indicate that nominal stress has a remarkable influence on mean $\mathrm{COF}$ and friction force. To investigate the effect of nominal stress on COF and friction force with different area ratio further, additional experiments under the condition of six nominal stress values $(1,250$, $1,875,2,500,3,125,5,000,6,250 \mathrm{~N} / \mathrm{m}^{2}$ ) with six different area ratios $(1.37 \%, 5.47 \%, 10.82 \%, 21.64 \%, 43.29 \%$, $86.58 \%$ ) were performed and repeated 10 times in each test. The variation of $\mathrm{COF}$ and friction force with nominal stress is represented in Fig. 10. Each data point is the average value of the $\mathrm{COF}$ or friction force of 10 experiments. As shown in the figure, the general tendency of COF with nominal stress is to increase first and then change smoothly, i.e., the effect of nominal stress on COF at different area ratio is the same. The reason for this behavior is related to the measurement of the maximum contact stress between single particle and the upper shale, calculated with Hertz Theory [24], as shown in Eq. (1), with the assumptions, for simplicity, that all different sizes of particles are equal spheres with a radius of $400 \mu \mathrm{m}$ and that both the shale and sand are in the scope of elasticity.

$$
\sigma_{H \max }=\frac{1}{\pi} \sqrt[3]{6 F\left\{\frac{\frac{1}{\rho_{1}}+\frac{1}{\rho_{2}}}{\frac{1-\mu_{1}^{2}}{E_{1}}+\frac{1-\mu_{2}^{2}}{E_{2}}}\right\}^{2}}
$$

In Eq. (1), $\sigma_{H \max }$ is the maximum contact stress, $F$ is measured by dividing the load by the number of sand particles and is the pressure of the contact zone 

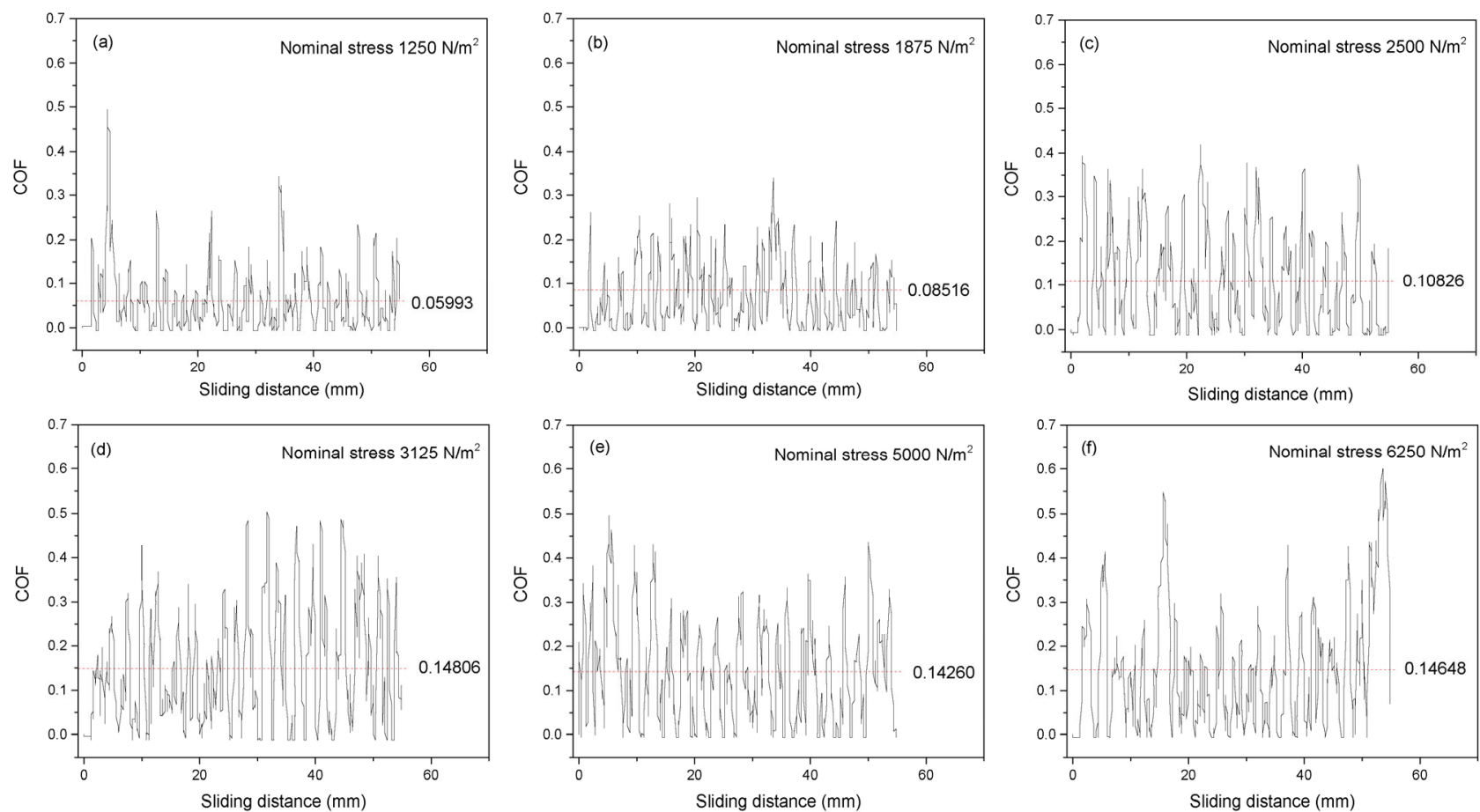

Fig. 7 Variation of COF with sliding distance of $55 \mathrm{~mm}$ under different nominal stress when the area ratio was $43.29 \%$. (a) $1,250 \mathrm{~N} / \mathrm{m}^{2}$, (b) $1,875 \mathrm{~N} / \mathrm{m}^{2}$, (c) $2,500 \mathrm{~N} / \mathrm{m}^{2}$, (d) $3,125 \mathrm{~N} / \mathrm{m}^{2}$, (e) $5,000 \mathrm{~N} / \mathrm{m}^{2}$, and (f) $6,250 \mathrm{~N} / \mathrm{m}^{2}$.
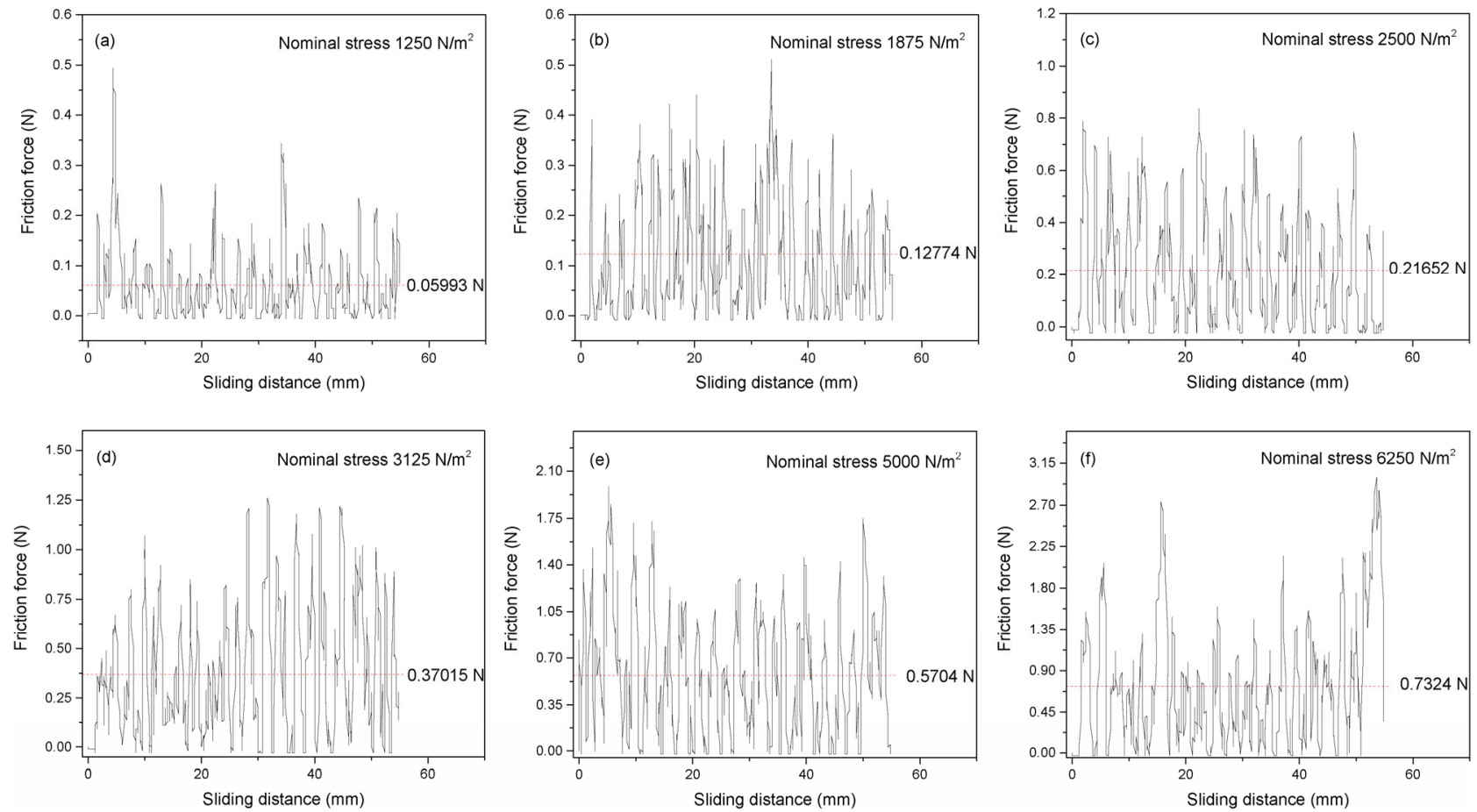

Fig. 8 Variation of friction force with sliding distance of $55 \mathrm{~mm}$ under different nominal stress when the area ratio was $43.29 \%$. (a) $1,250 \mathrm{~N} / \mathrm{m}^{2}$, (b) $1,875 \mathrm{~N} / \mathrm{m}^{2}$, (c) $2,500 \mathrm{~N} / \mathrm{m}^{2}$, (d) $3,125 \mathrm{~N} / \mathrm{m}^{2}$, (e) $5,000 \mathrm{~N} / \mathrm{m}^{2}$, and (f) $6,250 \mathrm{~N} / \mathrm{m}^{2}$.

between shale rock and single sand particle, and the curvature radius parameters of $\rho_{1}$ and $\rho_{2}$ for shale rock and sand particle are $\infty$ and $400 \mu \mathrm{m}$.
With different area ratio, the measurement of the contact stress with increasing nominal stress (Fig. 11) showed a trend that is exactly similar to that of COF, 


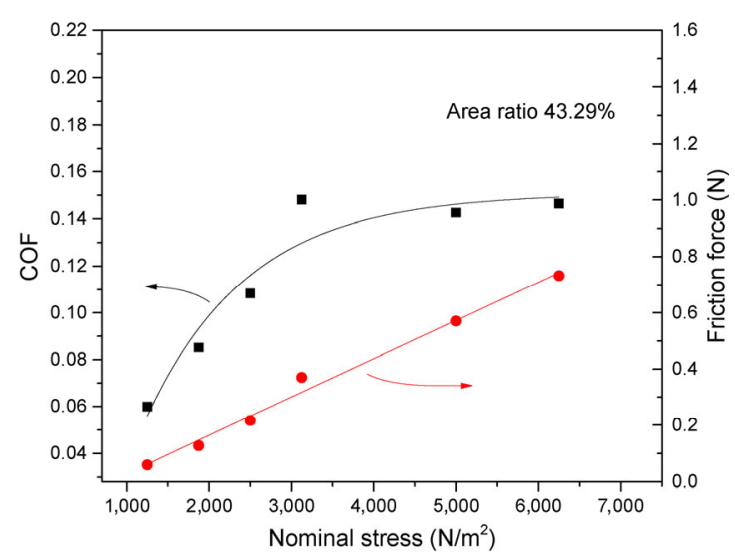

Fig. 9 Variation of the mean COF 0.05993, 0.08516, 0.10826, $0.14806,0.1426,0.14648$ and the mean friction force 0.05993 , $0.12774,0.21652,0.37015,0.5704 \mathrm{~N}$ with increasing nominal stress when the area ratio was $43.29 \%$.

indicating that there is an identical relation between the two: the higher the contact stress, the higher the COF. For the six area ratio conditions, the friction force curves showed a similar tendency, approximately increasing linearly with increasing nominal stress. According to the experimental results shown in Fig. 10, nominal stress is a significant impact factor for $\mathrm{COF}$ and friction force.

\subsection{Variation of COF with area ratio}

In Fig. 10, the slopes of the fitted straight line of friction force with nominal stress are different. To reflect the response of friction force to nominal stress better, an overall dynamic coefficient $\gamma$, defined as the plateau value of the increment of tangential friction force divided by that of load, was measured as the slopes divided by the upper surface of the upper shale rock. The values of the coefficient were $0.16906(1.37 \%$ area ratio), 0.14697 (5.47\% area ratio), 0.14354 (10.82\% area ratio), 0.16223 (21.64\% area ratio), 0.17424 (43.29\% area ratio), and 0.17133 (86.58\% area ratio). The reason for the different $\gamma$ values is the different area ratios. The variation of $\gamma$ with area ratio is shown in Fig. 12 . Interestingly, $\gamma$ first decreases and then increases with increasing area ratio, and the value of $\gamma$ at $10.82 \%$ area ratio is the approximate minimum. To explain this phenomenon, the contact stress with area ratio at different nominal stresses was obtained by Hertz Theory and is illustrated in Fig. 13. According to Fig. 13, with increasing area ratio, the contact stress decreases gradually at the same nominal stress. Consistent with the aforementioned, the lower the contact stress, the lower the COF, so the response of friction force to nominal stress decreases. This is one possible explanation for the decrease of $\gamma$ with increasing area ratio in the condition of area ratio lower than $10.82 \%$. However, with increasing area ratio, the distance between the sand particles decreases gradually,
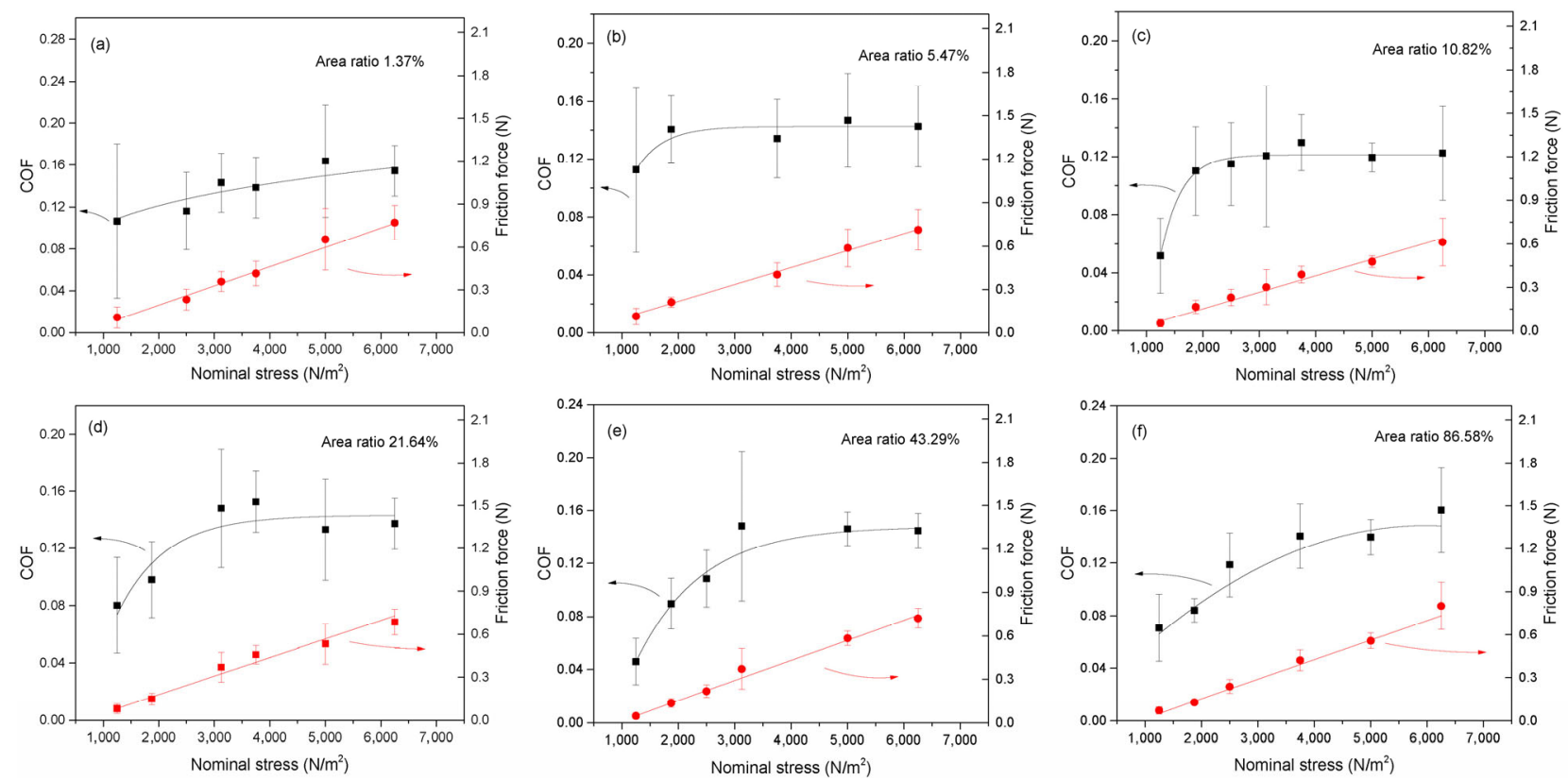

Fig. 10 Variation of the mean COF and friction force with increasing nominal stress in different area ratio. (a) $1.37 \%$, (b) 5.47\%, (c) $10.82 \%$, (d) $21.64 \%$, (e) $43.29 \%$, and (f) $86.58 \%$. 


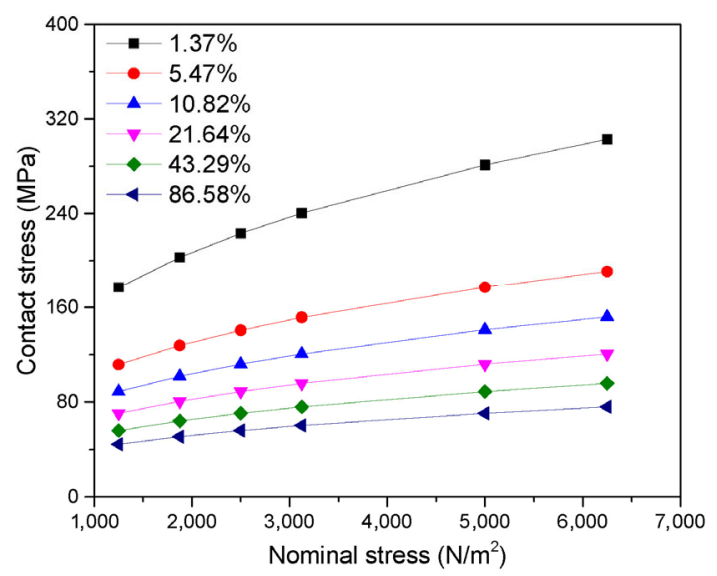

Fig. 11 The measurement of the contact stress varies with increasing nominal stress with different area ratio.

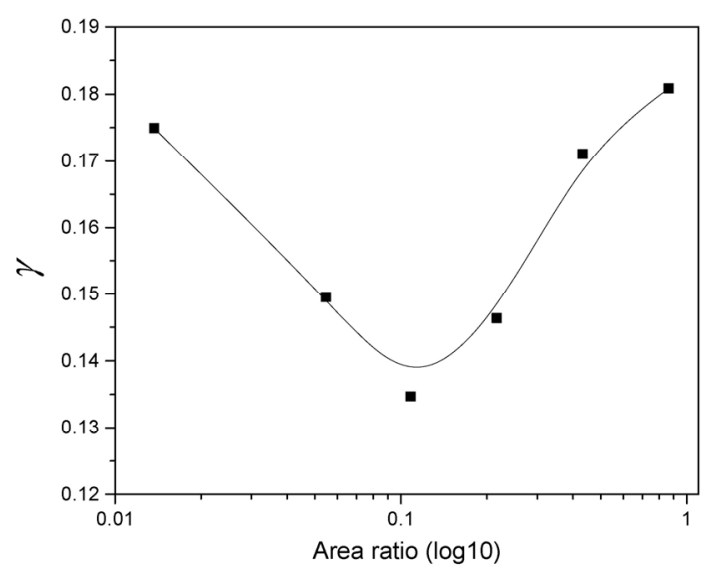

Fig. 12 The variation of $\gamma$ with increasing area ratio.

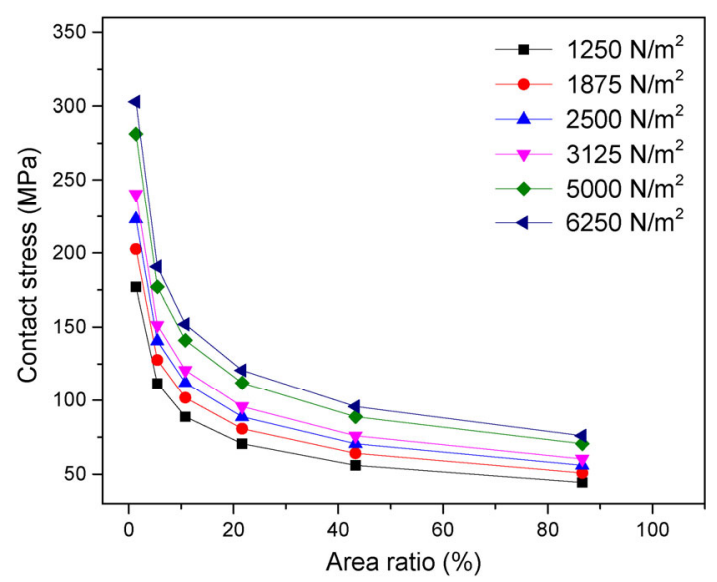

Fig. 13 The contact stress with increasing area ratio at different nominal stress.

and the interparticle friction force is not negligible. The model shale rock-sand particles experiment is shown in Fig. 14. As shown in the figure, particles of different sizes are distributed almost uniformly on the
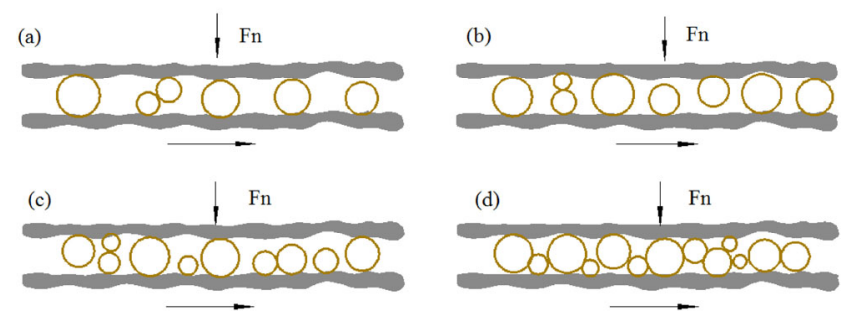

Fig. 14 The model shale rock-sand particles experiment.

shale rock. As the distance between the sand particles becomes shorter from Fig. 14(a) to Fig. 14(d), the interparticle friction force becomes progressively larger, which is considered to be one of the main possible reasons for the increase of $\gamma$ in the condition of area ratio greater than $10.82 \%$.

\section{Conclusions}

The frictional behaviors of the shale rock-dry quartz sand contact were investigated using a self-developed experimental system. The COF at the contact increases with nominal stress because of increasing contact stress under higher nominal stress, and the corresponding friction force increases linearly with increasingnominal stress. $\gamma$ first decreases and then increases with area ratio. At smaller area ratio, contact stress has a key influence on $\gamma$. At larger area ratio, increased $\gamma$ is attributable to decreased interparticle distance, for which the friction force is not negligible. The current study provides information helpful to originally understanding the frictional properties of the dry shale rock-dry quartz sand contact and an experimental foundation for further investigations of HF, other rockother sand contacts, and other industrial applications, including geothermal and mining applications.

\section{Acknowledgment}

Support by National Natural Science Foundation of China (No. 51575529) is acknowledged.

Open Access: The articles published in this journal are distributed under the terms of the Creative Commons Attribution 4.0 International License (http:// creativecommons.org/licenses/by/4.0/), which permits unrestricted use, distribution, and reproduction in any medium, provided you give appropriate credit to the 
original author(s) and the source, provide a link to the Creative Commons license, and indicate if changes were made.

\section{References}

[1] Fall A, Weber B, Pakpour M, Lenoir N, Shahidzadeh N, Fiscina J, Wagner C, Bonn D. Sliding friction on wet and dry sand. Phys Rev Lett 112(17): 175502 (2014)

[2] Xiao H P, Liu S H, Wang D G. Tribological properties of sliding shale rock-alumina contact in hydraulic fracturing. Tribol Lett 62(2): 20 (2016)

[3] Zhang S W. Green tribology: Fundamentals and future development. Friction 1(2): 186-194 (2013)

[4] Beste U, Lundvall A, Jacobson S. Micro-scratch evaluation of rock types - a means to comprehend rock drill wear. Tribol Int 37(2): 203-210 (2004)

[5] Yang H Q, Wang H, Zhou X P. Analysis on the rock-cutter interaction mechanism during the TBM tunneling process. Rock Mech Rock Eng 49(3): 1073-1090 (2016)

[6] Dougherty P S M, Mpagazehe J, Shelton J, Higgs III C F. Elucidating PDC rock cutting behavior in dry and aqueous conditions using tribometry. J Petrol Sci Eng 133: 529-542 (2015)

[7] Goldsby D L, Tullis T E. Low frictional strength of quartz rocks at subseismic slip rates. Geophys Res Lett 29(17): 25-1-25-4 (2002)

[8] Goldsby D L, Tullis T E. Flash heating leads to low frictional strength of crustal rocks at earthquake slip rates. Science 334(6053): 216-218 (2011)

[9] Chen X F. Rock friction and dynamic faulting at the micro-to nano-scales. Ph.D Thesis. Norman (USA): University of Oklahoma, 2015.

[10] Tullis T E. Rock friction and its implications for earthquake prediction examined via models of Parkfield earthquakes. Proc Natl Acad Sci USA 93(9): 3803-3810 (1996)

[11] Di Toro G, Goldsby D L, Tullis T E. Friction falls towards zero in quartz rock as slip velocity approaches seismic rates. Nature 427(6973): 436-439 (2004)

[12] Di Toro G, Hirose T, Nielsen S, Pennacchioni G, Shimamoto

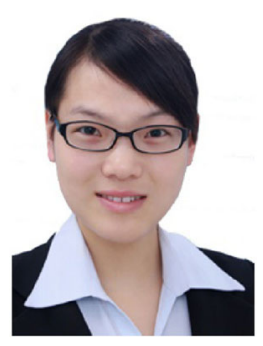

Huijie ZHANG. She received her bachelor degree in mechanical engineering and automation in 2015 from China University of Petroleum-
T. Natural and experimental evidence of melt lubrication of faults during earthquakes. Science 311(5761): 647-649 (2006)

[13] Reches Z, Lockner D A. Fault weakening and earthquake instability by powder lubrication. Nature 467(7314): 452-455 (2010)

[14] Stachowiak G W. How tribology has been helping us to advance and to survive. Friction 5(3): 233-247 (2017)

[15] Storti F, Billi A, Salvini F. Particle size distributions in natural carbonate fault rocks: Insights for non-self-similar cataclasis. Earth Planet Sci Lett 206(1-2): 173-186 (2003)

[16] Morgan J K. Numerical simulations of granular shear zones using the distinct element method: 2. Effects of particle size distribution and interparticle friction on mechanical behavior. J Geophys Res: Solid Earth 104(B2): 2721-2732 (1999)

[17] Wang T, Zhou W B, Chen J H, et al. Simulation of hydraulic fracturing using particle flow method and application in a coal mine. Int J Coal Geol 121: 1-13 (2014)

[18] Barati R, Liang J T. A review of fracturing fluid systems used for hydraulic fracturing of oil and gas wells. $J$ Appl Polym Sci 131(16): 40735 (2014)

[19] Holmberg K, Erdemir A. Influence of tribology on global energy consumption, costs and emissions. Friction 5(3): 263-284 (2017)

[20] Dougherty P S M, Pudjoprawoto R, Higgs III C F. Bit cutter-on-rock tribometry: Analyzing friction and rate-ofpenetration for deep well drilling substrates. Tribol Int 77: 178-185 (2014)

[21] Hsu S, Ying C, Zhao F. The nature of friction: A critical assessment. Friction 2(1): 1-26 (2014)

[22] Akrad O M, Miskimins J L, Prasad M. The effects of fracturing fluids on shale rock mechanical properties and proppant embedment. In SPE Annual Technical Conference and Exhibition, Denver, Colorado, USA, 2011.

[23] Dutta A K, Penumadu D. Hardness and modulus of individual sand particles using nanoindentation. In Geo-Denver 2007 Congress: New Peaks in Geotechnics, Denver, CO, 2007: $1-10$.

[24] Wang Q J, Zhu D. Hertz theory: Contact of spherical surfaces. In Encyclopedia of Tribology. Wang Q J, Chuang Y W, Eds. Boston, MA: Springer, 2013: 1654-1662.

Beijing, China. After then, she was PhD student in mechanical engineering at the same university. Her research interests include water-based lubrication and wear mechanism. 


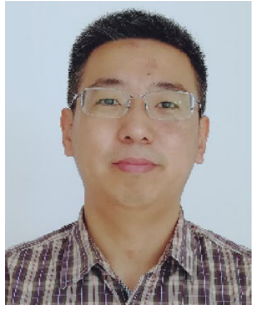

Shuhai LIU. He received his $\mathrm{PhD}$ degree in mechanical engineering in 2009 from Tsinghua University, Beijing, China. He joined the College of Mechanical and Transportation

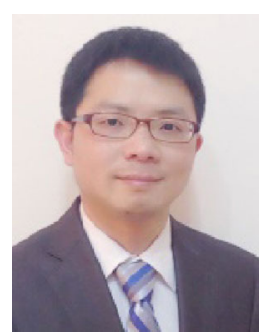

Huaping XIAO. He received his bachelor degree in 2006 from Tianjin University, Tianjin, China and master degree in 2011 from Tsinghua University, Beijing, China. He has earned $\mathrm{PhD}$ degree in mechanical engineering in 2014 from Texas
Engineering at China University of Petroleum-Beijing from 2009. His current position is a Professor and the Assistant Dean of the College. His research interests include tribology, surface science, and petroleum science.

A\&M University (TAMU), USA. He joined the College of Mechanical and Transportation Engineering at China University of Petroleum from 2014. His current position is an Associate Professor. His research areas include tribology properties and wear behaviors under complicated work condition and bio-related tribological systems. 